\title{
EXPERIMENTS AND PARAMETERIZED Finite ELEMENT Analysis of A Hemispherical PART Using Ansys $®$
}

\author{
SALEM, N. \& GREBEnisAn, G.
}

Abstract: To make a comparison with existing experimental results in the field today, and to determine experimental values other form-factor, were realized, testing of specimens produced from two different alloys based on Al (SUPRAL 100, FORMALL) of various thicknesses at various deformation temperatures. The experimental study was followed by a parameterized finite element analysis of the process, using Ansys ${ }^{\circledR}$ this is for considering the next step of our study, to compare experimental results with theoretical analysis, depending on two input parameters: and discuss the results. The parameterized analysis has the main objective to discover and emphasize the role of each input parameter on the evolution of the process, mainly on the output parameters, chosen by the operator. It is known that processing by superplastic forming is a process whose duration is superior to the similar plastic deformation processes, primarily due to the extremely low rate of deformation. This major disadvantage in the process economy and the calculation of economic efficiency is countered by the broad applicability of this process in areas of particular interest: aeronautics, automotive, medicine, and transport.

Key words: superplastic forming, finite element method, strain rate, aluminum alloy, gasostatic forming
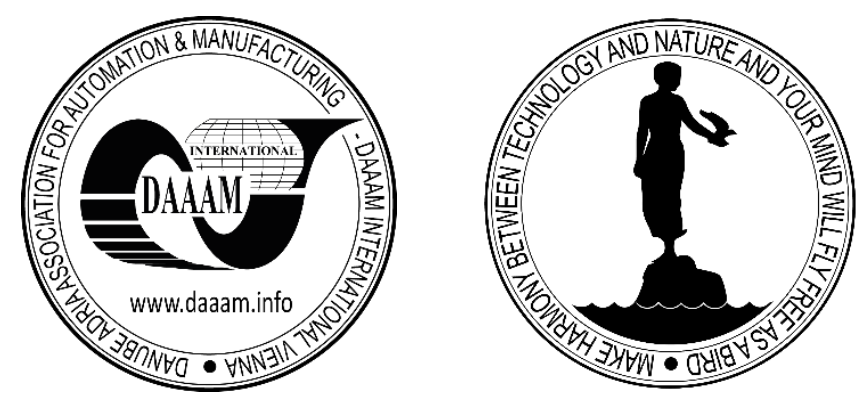

Authors' data: Salem, N[azzal]* \& Grebenisan, G[avril]**, * Zarqa University, Po Box 132222, Zarqa, Jordan, nsalem@zu.edu.jo ** University of Oradea, Str. Brandusei 8, 410541 Oradea, Romania, ggrebenisan@gmail.com

This Publication has to be referred as: Salem, N[azzal] \& Grebenisan, G[avril] (2017). Experiments and Parameterized Finite Element Analysis of a Hemispherical Part Using Ansys ${ }^{\circledR}$, Chapter 23 in DAAAM International Scientific Book 2017, pp.305-318, B. Katalinic (Ed.), Published by DAAAM International, ISBN 978-3902734-12-9, ISSN 1726-9687, Vienna, Austria

DOI: $10.2507 /$ daaam.scibook.2017.23 
Salem, N. \& Grebenisan, G.: Experiments and Parameterized Finite Element Analy...

\section{Introduction}

The superplasticity is a Metallurgical phenomenon that science implicitly recognized since early 1920, but before 1960 untapped, and the following definition is accepted: as the property of some materials, alloys and rare pure metal to exhibit a long and uniform deformation, without the appearance of local necking. The deformation depending on the speed of deformation, the deformation environment temperature, and the structure characteristic grain size below 10 micrometers.

The term "superplasticity" was introduced in 1945 by Bochvar A.A. \& Sviderskaia Z.A. [1], when they discover the behavior of the superplastic alloy $\mathrm{Zn}+$ $22 \% \mathrm{Al}$ eutectic, having performed ultrafine structure. $\mathrm{Zn}$ eutectic alloy of $22 \% \mathrm{Al}$ became then, in particular, the study of the superplastic material. Since 1960, the phenomenon has been investigated to (or "intending to") its practical application determined that the main conditions for the superplastic behavior development: grain sizes of $10 \mu \mathrm{m}$. The low-strain-rate (about $10^{-5}\left[\mathrm{~s}^{-1}\right]$ ), a relatively high temperature (> $0.5 \mathrm{~T}_{\text {melt }}$, where $\mathrm{T}_{\text {melt }}$ is the melting temperature of the alloy expressed in $[\mathrm{K}]$ ) at low values of deformation pressure.

The first tests which have demonstrated the existence of such properties to the alloy $\mathrm{Zn}+22 \% \mathrm{Al}$ were made in traction and extrusion, so that Backofen W.A., Turner I.R. \& Avery D.H. [2], to form, using air as a working medium, hollow parts with a rather complex configuration. They have used sheets of sheet thickness $\mathrm{s}=0.76[\mathrm{~mm}]$ in a die with a diameter of $100[\mathrm{~mm}]$, the air pressure $0.1-0.2[\mathrm{MPa}]$.

The particular structure, the most significant superplastic behavior constraint of the material property is ultra-fine grain size, wich should be below 10 micrometers. From the metallurgical phenomena that characterize the superplastic behavior, the balance between maintaining the ultrafine grain structure and grain growth (at the deformation temperature) is the main objective of the study of the superplastic behavior. Methods of refining the structure: separation of phases, the phase transformation heat or mechanical processing accompanied by the recrystallization are used for the majority of superplastic materials.

It is shown, however, that achieving ultrafine structures is not a sufficient condition to guarantee the behavior of a superplastic material, it must provide methods and conditions for maintaining fine grain size. Grain growth is punctuated in areas superplastic deformed and non-deformed areas are less (experimental observations).

The superplasticity is very often understood as a viscoplastic process because of stress deformation highly strain rate dependent. The superplastic behavior of materials is characterized by law established by Backofen W.A., Turner I.R. \& Avery D.H. [2]:

$$
\bar{\sigma}=K \cdot \dot{\bar{\epsilon}}^{m}
$$

wherein $K$ is the strength coefficient, and $m$ is the strain rate sensitivity index, the mathematical expression of which is given by the gradient of the logarithmic curve, so the logarithm of the stress (ln (stress)) on the logarithm of the rate of deformation (ln (strain-rate)). 
The strength coefficient, $K$, has the definition regarding stress, considering the strain rate at the value of unity. The physical dimension resides from above constitutive equation regarding components physical dimensions:

$$
[K]=\frac{[F]}{\left[L^{2}\right]}\left[T^{m}\right]
$$

The significance of the strain rate sensitivity in superplastic forming correspond to: the higher the value of $m$, there is no necking developed, and one obtains greater elongation, i.e. the ability of materials with this property, to exhibit greater deformation prior necking appearance. The significance of the strain rate sensitivity index, $m$, can be revealed by studying the deformation of the cylindrical gauge with area undistorted area A, length L and undergoing an initial load Dunne P. F. \& Petrinic N. [3]. Thus, undistorted gauge area is characterized by parameters $\mathrm{A}$, L, stress $\sigma$, strain rate $\dot{\varepsilon}$ while the deformed area will be characterized by $\mathrm{A}+\mathrm{dA}, \mathrm{L}+\mathrm{dL}, \sigma+\mathrm{d} \sigma, \dot{\varepsilon}+\mathrm{d} \dot{\varepsilon}$, respectively. The incompressibility condition of the test piece gives the following relationship, by neglecting the infinitesimal terms (like dAdL):

$$
A L=(A+d A)(L+d L) \approx A L+L d A+A d L
$$

one obtain

$$
\frac{d A}{d t}=-\dot{\varepsilon} A
$$

which, for deformed zone, become:

$$
\frac{d(A+d A)}{d t}=-(\dot{\varepsilon}+d \dot{\varepsilon})(A+d A)
$$

Or

$$
\frac{d}{d t}(d A) \approx-(A d \dot{\varepsilon}+\dot{\varepsilon} d A)=-\dot{\varepsilon} d A\left(\frac{A}{d A} \frac{d \dot{\varepsilon}}{\dot{\varepsilon}}+1\right)
$$

As the force is constant, we obtain:

$$
\sigma A=(\sigma+d \sigma)(A+d A), \text { or } \frac{d \sigma}{\sigma}=-\frac{d A}{A}
$$

Applying the constitutive equation, expressed in effective values: $\sigma=K \dot{\varepsilon}^{m}$, one obtain:

$$
\sigma+d \sigma=K(\dot{\varepsilon}+d \dot{\varepsilon})^{m}=K \dot{\varepsilon}^{m}\left(1+\frac{d \dot{\varepsilon}}{\dot{\varepsilon}}\right)^{m}=K \dot{\varepsilon}^{m}\left[1+m \frac{d \dot{\varepsilon}}{\dot{\varepsilon}}+\cdots\right]
$$


Salem, N. \& Grebenisan, G.: Experiments and Parameterized Finite Element Analy...

This relationship may be written as:

$\frac{d \sigma}{\sigma} \approx m \frac{d \dot{\varepsilon}}{\dot{\varepsilon}}$, or $\frac{A}{d A} \frac{d \dot{\varepsilon}}{\dot{\varepsilon}}=-\frac{1}{m}$

so that

$$
\frac{d}{d t}(d A) \approx-d A \dot{\varepsilon}\left(1-\frac{1}{m}\right)
$$

This ultimate equation shows that de deformation quantity, $\frac{d}{d t}(d A)$, depends on value of $\left(1-\frac{1}{m}\right)$. We may observe that when the strain rate sensitivity, $\mathrm{m}$, increases (and take the value of unity), the necking, $\frac{d}{d t}(d A)$, decreases to zero, as value.

Based on applying the membrane theory, to reveal the stress state in a thin sheet loaded by pressure $P$, with $s$ as thickness, $R_{\theta}$ and $R_{\varphi}$ are the curvature radii $\left(R_{\theta}-\right.$ meridian radius; $R_{\varphi}$ - tangential radius), fig. 1, the relationship may describe a state of equilibrium, Giuliano, G. [4]:

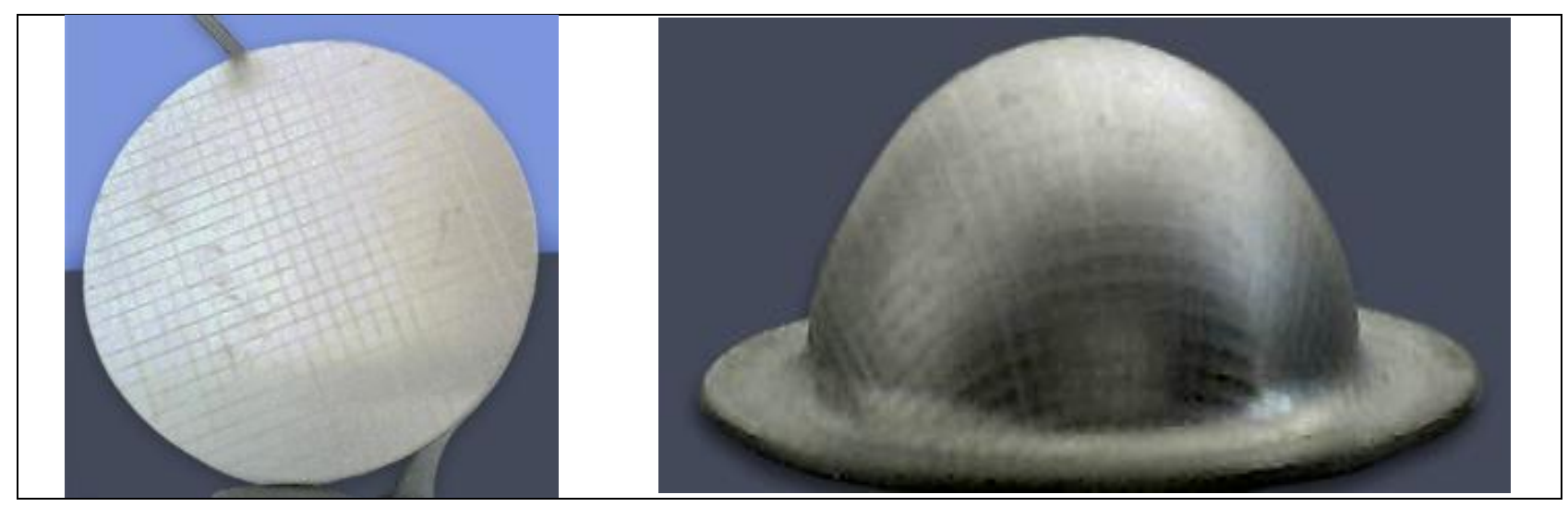

Fig. 1. The sample(before the forming)-left; The part, superplastic formed-right, Grebenisan G. \& Muresan S. [5]

Follow this,

$$
2 \sigma_{\varphi} \sin \left(\frac{d \varphi}{2}\right) s R_{\theta} d \theta+2 \sigma_{\theta} \sin \left(\frac{d \theta}{2}\right) s R_{\varphi} d \varphi=p R_{\varphi} d \varphi R_{\theta} d \theta
$$

moreover, assuming that for a small angle, $\sin \left(\frac{d \varphi}{2}\right) \cong \frac{d \varphi}{2}$, this equation may be written as:

$\frac{\sigma_{\varphi}}{R_{\varphi}}+\frac{\sigma_{\theta}}{R_{\theta}}=\frac{p}{S}$ 
Using the relationships $\sigma_{\theta} \sin (\varphi) \cdot 2 \pi r s=p \pi r^{2}$, and $r=R_{\varphi} \sin (\varphi)$ the tangential stress, and the circumferential stress are estimated, respectively, as:

$$
\begin{aligned}
\sigma_{\theta} & =\frac{p R_{\varphi}}{2 s} \\
\sigma_{\varphi} & =\frac{p R_{\varphi}}{2 s}\left(2-\frac{R_{\varphi}}{R_{\theta}}\right)
\end{aligned}
$$

The von Mises criterion gives the equivalent stress, for plain stress condition(the thickness stress $\sigma_{t}=0$ ):

$$
\bar{\sigma}=\sqrt{\sigma_{\theta}^{2}+\sigma_{\varphi}^{2}-\sigma_{\theta} \sigma_{\varphi}}=\frac{p R_{\varphi}}{2 s} \sqrt{\left(\frac{R_{\varphi}}{R_{\theta}}\right)^{2}-3 \frac{R_{\varphi}}{R_{\theta}}+3}
$$

Assuming that the elastic strain is negligible, a relationship between stresses and strains in the plastic domain, one can be established, using the Levy-Mises flow rule, one obtain the expressions for tangential $\left(\dot{\varepsilon}_{\theta}\right)$, circumferential $\left(\dot{\varepsilon}_{\varphi}\right)$ and thickness $\left(\dot{\varepsilon}_{t}\right)$ strain rate:

$$
\begin{aligned}
& \dot{\varepsilon}_{\theta}=\frac{\dot{\bar{\varepsilon}}}{\bar{\sigma}}\left[\sigma_{\theta}-\frac{1}{2}\left(\sigma_{\varphi}+\sigma_{t}\right)\right] \\
& \dot{\varepsilon}_{\varphi}=\frac{\dot{\bar{\varepsilon}}}{\bar{\sigma}}\left[\sigma_{\varphi}-\frac{1}{2}\left(\sigma_{\theta}+\sigma_{t}\right)\right] \\
& \dot{\varepsilon}_{t}=\frac{\dot{\bar{\varepsilon}}}{\bar{\sigma}}\left[\sigma_{t}-\frac{1}{2}\left(\sigma_{\varphi}+\sigma_{\theta}\right)\right]
\end{aligned}
$$

It is easy to observe that these relationships are similar with those from elasticity theory with some corrections. Considering the volume constancy $\left(\varepsilon_{\theta}+\varepsilon_{\varphi}+\varepsilon_{t}=\right.$ const, $\dot{\varepsilon}_{\theta}+\dot{\varepsilon}_{\varphi}+\dot{\varepsilon}_{t}=0$ ), the equivalent strain rate, calculated based on von Mises criterion is:

$$
\dot{\bar{\varepsilon}}=\frac{2}{\sqrt{3}} \sqrt{\dot{\varepsilon}_{\theta}^{2}+\dot{\varepsilon}_{\varphi}^{2}+\dot{\varepsilon}_{\theta} \dot{\varepsilon}_{\varphi}}
$$

The part analyzed is a sphere, by definition, $R_{\theta}=R_{\varphi}=R$, so one may write:

$$
\begin{gathered}
\sigma_{\theta}=\sigma_{\varphi}=\frac{p R}{2 s} \text { and Levy- Mises equations are: } \\
\dot{\bar{\varepsilon}}=-\dot{\varepsilon}_{t}=2 \dot{\varepsilon}_{\theta}=2 \dot{\varepsilon}_{\varphi}
\end{gathered}
$$


From experience, were found that the stresses and strains are in the following relationships:

$$
\begin{aligned}
& \sigma_{\theta}=\frac{p R}{2 s} \\
& \sigma_{\varphi}=\frac{\sigma_{\theta}}{2} \\
& \bar{\sigma}=\sqrt{3} \cdot \sigma_{\varphi}=\frac{\sqrt{3}}{2} \sigma_{\theta}
\end{aligned}
$$

moreover, strains are:

$$
\begin{aligned}
& \dot{\varepsilon}_{\theta}=0 \\
& \dot{\varepsilon}_{\varphi}=-\dot{\varepsilon}_{t} \\
& \dot{\bar{\varepsilon}}=\frac{2}{\sqrt{3}} \dot{\varepsilon}_{\varphi}=-\frac{2}{\sqrt{3}} \dot{\varepsilon}_{t}
\end{aligned}
$$

Using the assumptions of Jovane F. [6], also Enikeev F.U. \& Kruglov A.A [7], respectively, of which the thickness is uniform on all directions, one may obtain a calculus relationship for R and average thickness, $\bar{s}$, respectively, :

$$
R=\frac{a^{2}+h^{2}}{2 h}
$$

And

$$
\bar{s}=s_{0} \frac{a^{2}}{a^{2}+h^{2}}
$$

where $\mathrm{h}$ is the sphere height at the moment $\mathrm{t}$, and $\mathrm{a}$ is the initial radius of the sample sheet (the input parameter Sample_diameter)

For an optimal strain rate, $\dot{\bar{\varepsilon}}_{\text {opt }}$, at which one may consider that the forming process occurs, i.e. the strain rate that the sensitive index $m$ has the highest value, and the process temperature pre-chosen, Giuliano G. [4] had obtained the expressions for the preasure, as function of the sphere relative height, $\mathrm{H}=\mathrm{h} / \mathrm{a}$ :

$$
\bar{\sigma}=\frac{p a}{4 s_{0}} \frac{\left(1+H^{2}\right)^{2}}{H}
$$




$$
\dot{\bar{\varepsilon}}=\frac{2 H}{1+H^{2}} \cdot \dot{H}
$$

And

$$
p=\frac{4 s_{0} K \dot{\bar{\varepsilon}}_{o p t}^{m}}{a} \frac{H}{\left(1+H^{2}\right)^{2}} ; \text { where } H=\sqrt{e^{\dot{\bar{\varepsilon}}_{o p t} t}-1}
$$

Given the strain rate used, $\dot{\bar{\varepsilon}}=10^{-3}\left[\mathrm{~s}^{-1}\right]$, the part were formed in 5700 seconds, while calculus using the relationship obtained for $\mathrm{H}(22.4 \mathrm{~mm})$ given $\mathrm{us} \mathrm{t}=6221$ seconds, which is satisfactory for this forming process.

An absorbing work is Naceur, H., Guo, Y.Q. \& J.-L. Batoz [9], in which the authors present a complete mathematical algorithm for solving the inverse problem, i.e. determining the optimal geometric model for the blank if the computational results of the simulation of the plastic deformation process are known, and the finite element analysis of this process was accomplished.

\section{Superplastic Forming and Parameterized Analysis}

The specimens used for the experimental determinations were cut from the sheet with thickness: $0.8 ; 1,2 ; 1.29$, respectively $2.0[\mathrm{~mm}]$; and diameters 44.5 and 51 respectively (Fig. 2).

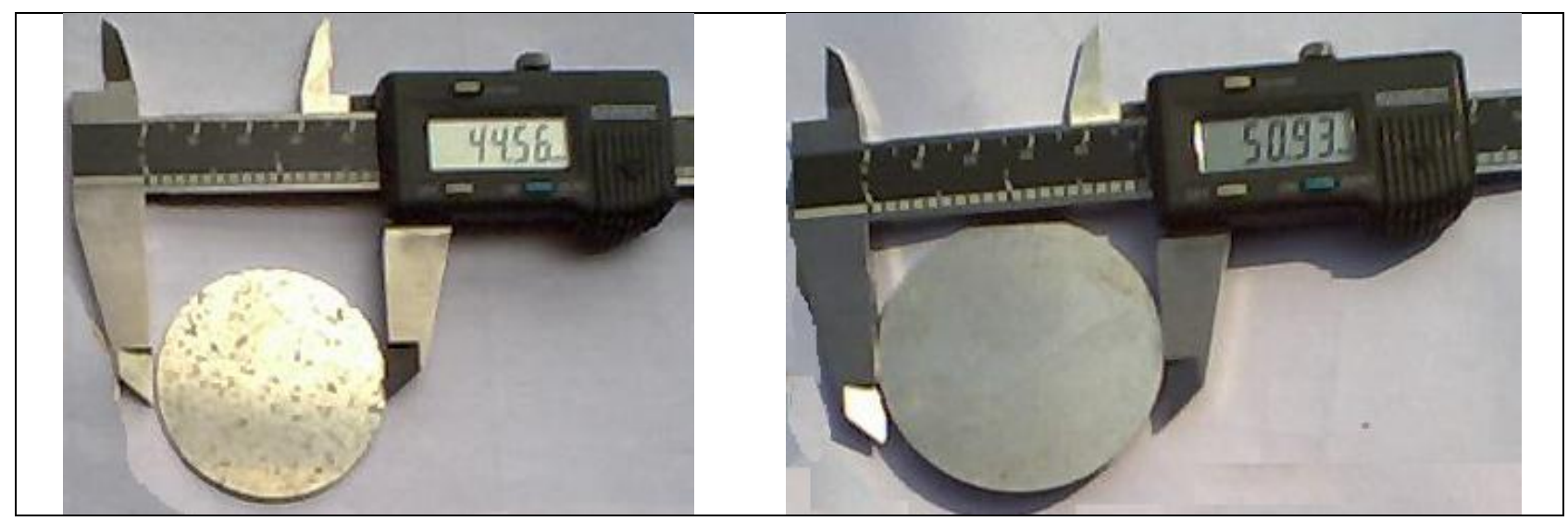

Fig. 2. The specimens used for superplastic forming Grebenisan G. \& Muresan S. [8]

\section{Experiment} follows:

Experimental tests were performed on 11 samples divided into two groups, as

$-\mathrm{I}^{\mathrm{st}}$ set. Some 8 samples, cut out from Supral 100 alloy, with a diameter of 44.5 $[\mathrm{mm}]$; and thickness of $0.8[\mathrm{~mm}]$, tested as following deformation parameters:

- - one sample was tested at deformation temperature: $\mathrm{T}_{\text {def }}=450\left[{ }^{\circ} \mathrm{C}\right]$; 
Salem, N. \& Grebenisan, G.: Experiments and Parameterized Finite Element Analy...

- -4 specimens were deformed at deformation temperature $\mathrm{T}_{\text {def }}=460\left[{ }^{\circ} \mathrm{C}\right]$;

- - one specimen was tested at deformation temperature $\mathrm{T}_{\text {def }}=470\left[{ }^{\circ} \mathrm{C}\right]$;

- - one specimen was tested at deformation temperature $\mathrm{T}_{\mathrm{def}}=480\left[{ }^{\circ} \mathrm{C}\right]$;

- - one specimen was tested at deformation temperature $T_{\text {def }}=500\left[{ }^{\circ} \mathrm{C}\right]$;

- - All specimens from this set were tested at strain rate $2.5 \times 10^{-3}\left[\mathrm{~s}^{-1}\right]$

-II ${ }^{\text {nd }}$ set. -a number of 3 specimens, cut out from FORMALL alloy, whith a diameter of $51[\mathrm{~mm}]$, thickness $1.2[\mathrm{~mm}]$, deformed at $\mathrm{T}_{\text {def }}=510\left[{ }^{\circ} \mathrm{C}\right]$, at strain rate $10^{-}$ ${ }^{4}\left[\mathrm{~s}^{-1}\right]$

\section{The forming die, the project installation and superplastic forming results}

\subsection{The forming die}

The superplastic deformation die, (Fig. 3), was produced of stainless steel and consists of two half-die assembled through G13 / 4" thread. For the air access inside the die, during the deformation process, two cylindrical rods made of stainless steel, having $300 \mathrm{~mm}$ orifices were provided. The "lower" half-die, which gives the final shape of the piece, has a circular area with diameter $\emptyset 32[\mathrm{~mm}]$ and height of $6[\mathrm{~mm}]$. This area is designed to reduce, even cancel, the friction between the sample and the die, during the gasostatic forming. The spherical area simulates the minimum possible cross-sectional rays to be achieved in parts obtained by superplastic deformation processes, with no local thinning (necking).

To seal the active zones between the sample and the upper die, a copper sealing washer is provided, and in the lower part, this is achieved by the ribbon with the connection radius.

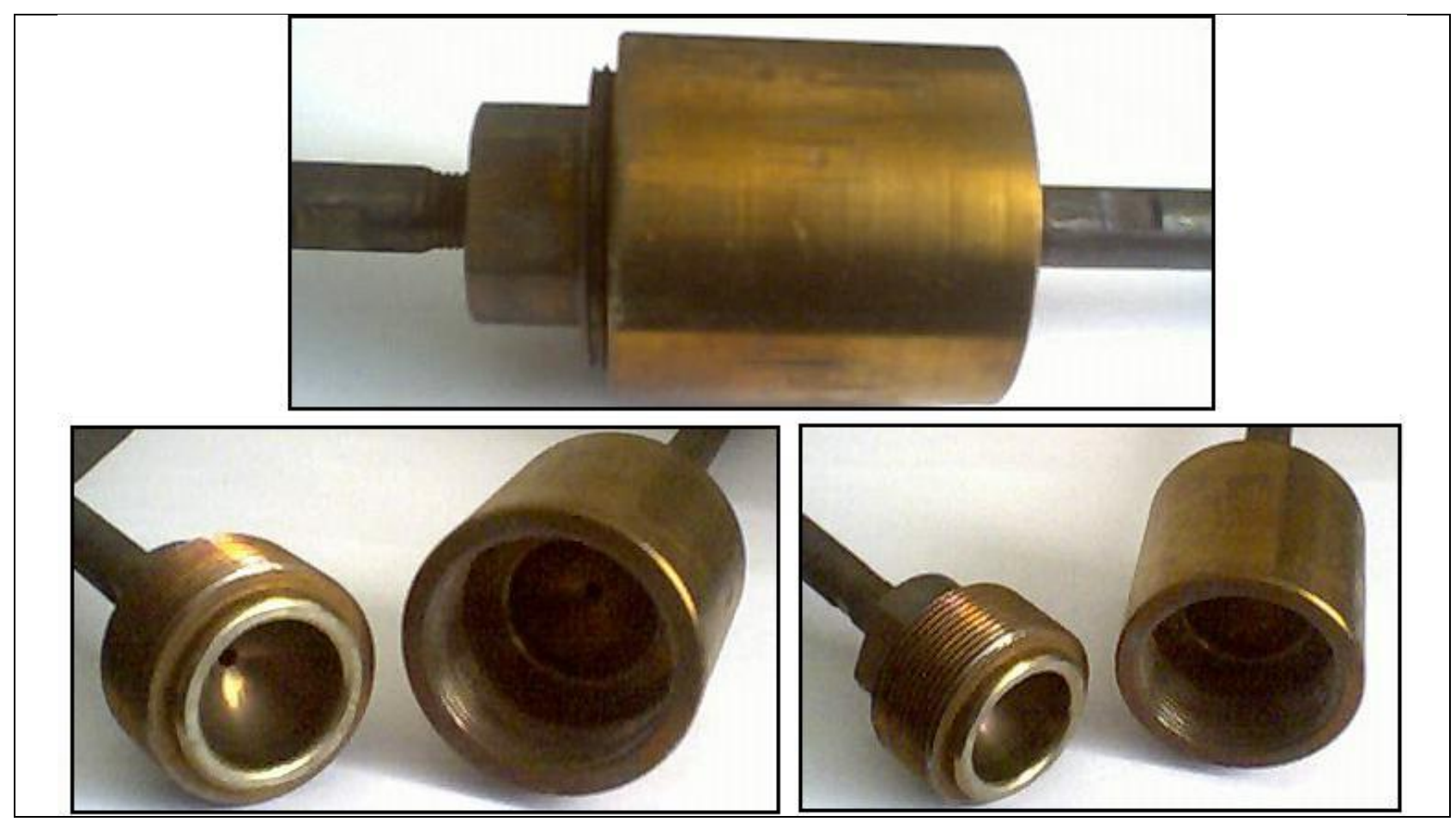

Fig. 3. The superplastic forming die Grebenisan G. \& Muresan S. [8] 


\subsection{The Superplastic Forming Installation (Fig. 4)}

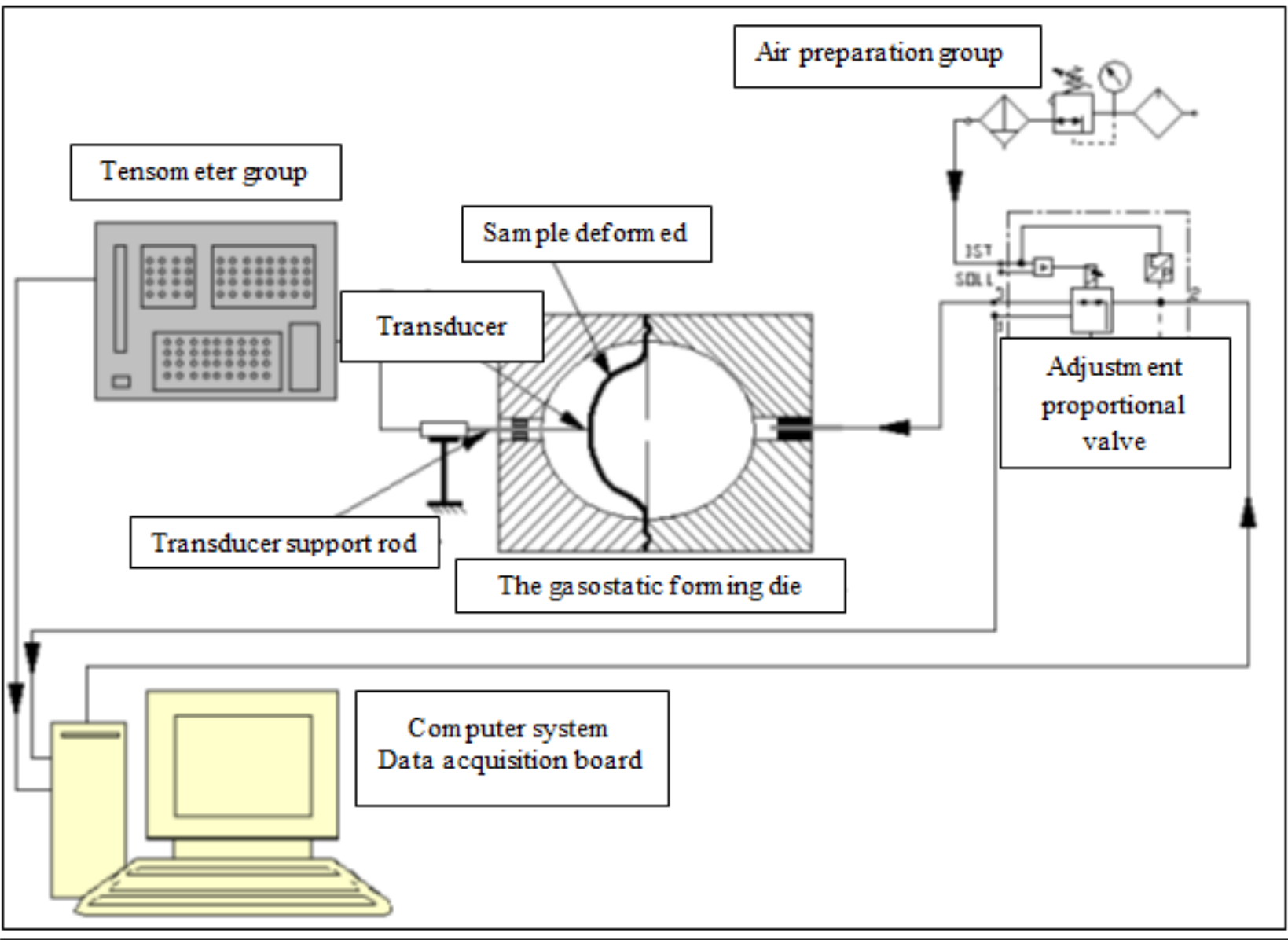

Fig. 4. The superplastic forming installation scheme Grebenisan G. \& Muresan S. [8]

The data acquisition from the transducer is made as follows: one the computation of the strain rate is accomplished, using the time base of the calculation system and, as the data is acquired, the actuator voltage of the proportional coil of the pressure regulator is controlled in such a way that the instance speed is as close as possible to a required reference speed imposed by the operator. As the process evolves, the data acquired from the transducer (based on which the speed is being calculated) and the data from the pressure transducer are written into a file automatically saved on the computer's hard disk, which is then used at the analysis of the superplastic deformation process.

\subsection{The Parameters of Experiments Performed}

\subsubsection{Forming Pressure}

The working pressure is determined using the relationship $\bar{\sigma}=\frac{p a}{4 s_{0}} \frac{\left(1+H^{2}\right)^{2}}{H}$, above founded for constant pressure forming medium, Giuliano, G. \& Franchitti, S. [10]. The analytically determined air pressure is: $\mathrm{p}=0.69585[\mathrm{MPa}]=6.82404$ [bar], using the reference value $\mathrm{p}=0.7 \pm 0.01[\mathrm{MPa}]$, Kappes, J., Liewald, M., Jupp, S., Pirchl, C. \& Herstelle, R. [11]. 


\subsubsection{The Strain Rate}

The strain rate, as a driven element in the pressure adjustment process, by the proportional pressure regulator(proportional valve) inside the die, and is achieved analytically considering the deformation of a curvilinear element in the spherical workpiece. Respecting the theoretical considerations one may calculate the equivalent strain rate: $\dot{\bar{\varepsilon}}=\frac{2 H}{1+H^{2}} \cdot \dot{H}$. This being necessary to achieve the actual strain rate of the blank. Since, from experimental data, it was found that the superplastic strain rate $\varepsilon=2.5 \times 10^{-3}\left[s^{-1}\right]$ for SUPRAL 100 and $\varepsilon=10^{-4}\left[s^{-1}\right]$ FORMALL, respectively. It follows that for the semifinished product with thickness $\mathrm{s}=0.8[\mathrm{~mm}]$, the actual sample deformation velocity is $0.02[\mathrm{~mm} / \mathrm{s}]$ and $0.0012[\mathrm{~mm} / \mathrm{s}]$, respectively, for the sample of thickness $\mathrm{s}=1.2[\mathrm{Mm}]$, Xing, H.L. \& Wang, Z.R. [12].

\subsubsection{Forming Temperature}

The optimal deformation temperature for the SUPRAL 100 alloy is $\mathrm{T}_{\text {def }}=460\left[{ }^{\circ} \mathrm{C}\right]$ and for the FORMALL alloy is $\mathrm{T}_{\text {def }}=510\left[{ }^{\circ} \mathrm{C}\right]$, but experimental tests have also been performed at other deformation temperatures to study temperature influence on the necking and drawing depth, Chenot, J.-L. \& Massoni, E. [13] and Bonet, J. \& Gil, A. J. [14].

\subsection{Results and discussions}

The 11 pieces, fig. 5, made by superplastic deformation fit perfectly into our expectations regarding the behavior of the alloy material chosen for the current study. The advantages of superplasticity consist primarily in high deformability, possibly in the case of materials possessing these characteristics, uniform strain deformation, and the complexity of possible geometric shapes without a special manufacturing and constructional precondition. Thus, the extremely low cost of superplastic deformation tools, combined with the advantages listed, recommends this process, particularly when superior plastic deformation technologies (into the cold or hot medium) do not work, or the results are inadequate. The case of Ti-based alloys, non-deformable by usual processes, is prototypical to argue for the choice of superplastic deformation processes for some types of materials. The decision to process by a special procedure, such as superplastic deformation, should, however, be based on well-documented analyzes and studies both on deformability of materials and on the performance of the operation itself.

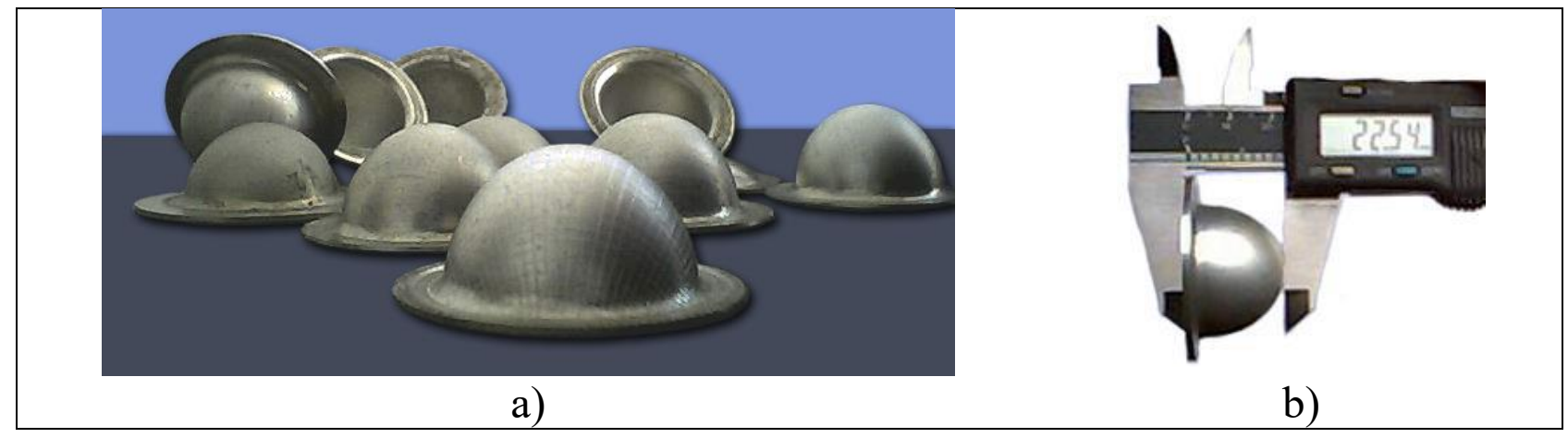

Fig. 5. a)- The group of performed workpieces b)- The height/diameter of superplastic deformed spherical cupola Grebenisan G. \& Muresan S. [8] 


\section{The Finite Element Analysis of Superplastic Bulging}

\subsection{Material Parameters}

The simulation of superplastic forming and analysis performed were carried out using Ansys $^{\circledR}$ software. While setup the material's properties, for Supral 100, aluminum based alloy, an Anand Viscoplasticity as a material model were chosen, Brown, S. B., Kim, K. H. \& Anand, L. [15] and Anand, L. [16], respectively. The characteristic parameters in Table 1 are given, by Ganapathysubramanian, Sh. \& Zabaras, N. [17]:

\begin{tabular}{|c|c|c|c|}
\hline Property & Symbol & Value & Units \\
\hline Initial Deformation Resistance & $\mathrm{S}_{0}$ & 29.7 & $\mathrm{MPa}$ \\
\hline $\begin{array}{c}\text { Activation Energy/Universal Gas } \\
\text { Constant }\end{array}$ & $\mathrm{Q} / \mathrm{R}$ & 21086 & $\mathrm{~K}^{-1}$ \\
\hline Pre- exponential Factor & $\mathrm{A}$ & $1.90593 \mathrm{e}+7$ & $\mathrm{~s}^{-1}$ \\
\hline Multiplier of Stress & $\xi$ & 7 & \\
\hline Strain Rate Sensitivity of Stress & $\mathrm{m}$ & 0.23348 & \\
\hline $\begin{array}{c}\text { Coefficient for Deformation Resistance } \\
\text { Saturation }\end{array}$ & $\mathrm{h}_{0}$ & 1115.6 & $\mathrm{MPa}$ \\
\hline $\begin{array}{c}\text { Strain Rate Sensitivity of Saturation } \\
\text { Strain Rate Sensitivity of Hardening or } \\
\text { Softening }\end{array}$ & $\mathrm{n}$ & 18.92 & $\mathrm{MPa}$ \\
\hline
\end{tabular}

Tab. 1. Properties

The Anand Viscoplasticity characteristics were experimentally verified and describe quite well the material of Aluminium alloy chosen for superplastic forming, Supral 100. The optimal superplastic deformation temperature is situated in the range of $400-480\left[{ }^{\circ} \mathrm{C}\right]$.

Some of material mechanical properties are:

- Optimal strain rate: 0.0005 to $0.01\left[\mathrm{~s}^{-1}\right]$;

- Tensile Strength, Yield: 25 [MPa];

- Tensile Strength, Ultimate : 75 to 105 [MPa];

- Breaking elongation: up to $1800 \%$;

- Grain size: $3-6 \times 10^{-3}[\mathrm{~mm}]$;

To perform the optimization procedure and study of the behavior of material during superplastic forming, the first input parameter Displacement Y Component was chosen and the second input parameter has been selected, Sample_diameter. The parameterized analysis has the main objective to discover and emphasize the role of each input parameter on the evolution of the process, mainly on the output parameters, chosen by the operator. To determine the degree of influence and the gradual importance of input parameters, we used the parameter correlation tool(fig. 6, a)): 


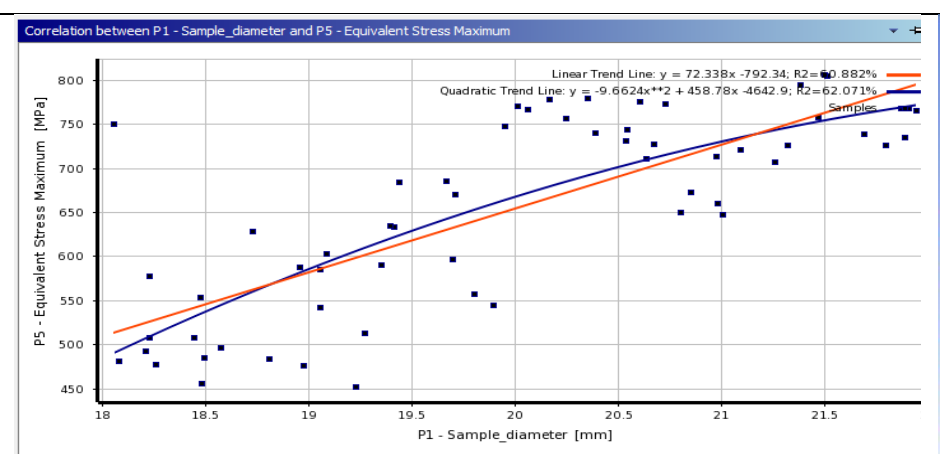

a)

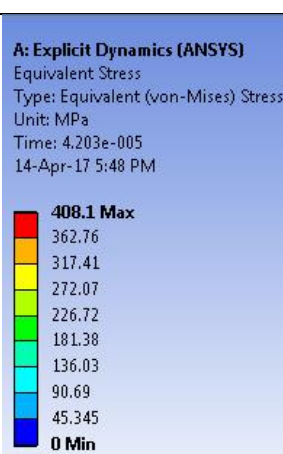

b)

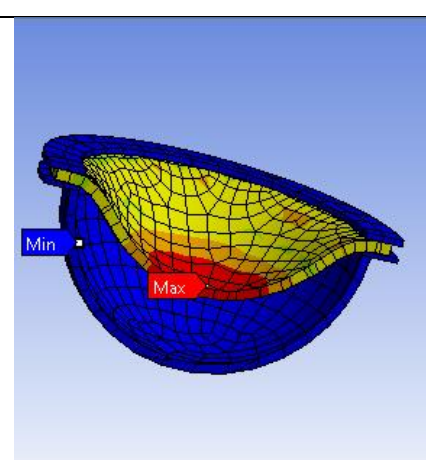

c)

Fig. 6. Equivalent Stress (von Mises), a)-The correlation between input parameter (Sample_diameter) and output parameter (Equivalent Stress), b)- Computed values of Equivalent Stress (Finite Element Method), c)-Distributed map of Equivalent Stress - a sequence of forming process

The finite element analysis revealed and confirmed the material behavior and the predicted uniformity of samples' thickness, fig. 6, b,c), Jarrar, F., [18], Guo, M.-L., Liu, J., Tan, M.-J., Chua, B.-W., [19].

\section{Conclusion}

By the research carried out and presented in the paper, the following conclusions can be drawn:

The superplastic properties of the material are determined by its granular microstructure. To demonstrate this, we analyzed microscopically two metallographic samples taken from each alloy, and faced the microscopic images of the metal specimen and those of the extruded blank, with obvious differences between the structures of the two samples. The grain size, measured in the two directions, on the plate samples, falls within the limits of theoretical prescriptions of superplastic behavior: the grains being coaxial. Agglomerations of impurities, reduced in volume or material vacancies have been observed, but these fall within the limits of the superplastic conditions. Under these circumstances, we considered that, structurally, the specimen met the preliminary conditions of superplasticity.

The embossed pieces have a surface without rickshaws or individual variations in thickness.

The cracks appeared only in the pole of the specimen, at two workpieces, which demonstrates how to deform and modify the shape of the piece during the gasostatic stamping. Thus, it can be concluded that the specimen deforms from the center to the retention limits in the die, the material constantly flows but at different speeds in the free zones of constraints.

The thickness of the material was recorded in the area of the flange sphere radius following a law of identical variation on all specimens.

There was no occurrence of the "quench" phenomenon of the flange. Moreover, the flange in all cases had the final dimension identical to the initial one.

It has been found that there is an area of dimensional stability and almost zero variation of the thickness of the workpiece in the sphere and, to some degree, in the field of the connection radius. This phenomenon is due to the uniform deformation velocity under conditions of uniformly distributed stress. 
In the spherical area of the formed parts, the law of variation of the cross-sectional dimensions is linear, the slope of the straight line increasing in the sense of reducing the dimensions (in absolute values). The explanation of this phenomenon is the way of realizing the superplastic deformation by free molding, without friction with the mold. As the deformation occurs without contact with the mold elements, the material flows without constraints at a constant deformation rate. This observation is consistent with the layout of the network, a priori, on the specimen.

The mesh is drawn on the sample (squares at initial) turned into curved quadrilaterals with equal sides after deformation. These linear geometric elements, on the outer surface of the spherical dome, are dimensionally and morphologically identical on a spherical cap, approximated to $20 \%$ of the total height of the embossed part. Beginning from this height in the meridian direction to the flange of the embroidered piece, the elements of the two-dimensional mesh change their shape and dimensions, respecting the law of variation of the thickness of the piece (with absolute values). Thus, while at the top of the spherical dome, the deformed quadrilaterals are identical on a spherical area, towards the base of the hemisphere, the quadrilaterals have curvilinear shapes with progressively smaller dimensions.

The finite element analysis of superplastic deformation has demonstrated the existence of an infinitesimal thinning of the thickness of the deformed piece. According to this analysis, it was found that the deformation is quasi-uniform across the entire hemisphere section.

At the maximum deformation depth, i.e. in the hemisphere's pole, there is emphasized a state of stress, which explains the cracking of some of the deformed parts. By finite element analysis, we demonstrated that it is very clear the superplastic deformation should be performed with quasi-constant pressure, with subtle variations on the time unit, the necking process to be avoided.

\section{References}

Bochvar, A.A., \& Sviderskaia, Z.A. (1945). Superplasticity in Zinc-Aluminum Alloys, Izv. Akad. Nauk SSSR, Otd. Tekh. Nauk, 9, 821-827.

Backofen, W.A., Turner, I.R. \& Avery D.H. (1964). Superplasticity in an Al-Zn Alloy, Trans. ASM, 57, pp. 980-990.

Dunne, F. \& Petrinic, N. ( 2005). Introduction to Computational Plasticity, Oxford University Press.

Giuliano, G. (2011). Superplastic forming of advanced metallic materials, methods and applications, Oxford, (C) Woodhead Publishing Limited.

Grebenisan, G. \& Muresan, S. (2007). Numerical Study Of Volumic Forming On Superplastic Behaviour, Annals of The University of Oradea. Fascicle of Management and Technological Engineering, Volume XVI (VI), ISSN 1583-0691, DOI: 10.15660/AUOFMTE.2007.714.

Jovane, F. ( 1968). An approximate analysis of the superplastic forming of a thin circular diaphragm: theory and experiments, Int. J. Mech. Sci., Pergamon Press. Vol. 10, pp. 405-427. Printed in Great Britain.

Enikeev, F.U. \& Kruglov, A.A. (1995). An analysis of the superplastic forming of a thin circular diaphragm International Journal of Mechanical Science, 37 ( 5 ): 473 483 
Grebenisan, G. \& Muresan, S. (2007). Numerical analysis approach of superplastic deformation and gasostatic forming modeling, Annals of The University of Oradea. Fascicle of Management and Technological Engineering, DOI: 10.15660/AUOFMTE.2007.715, Volume XVI (VI), ISSN 1583-0691.

Naceur, H., Guo, Y.Q. \& Batoz, J.-L. (2004). Blank optimization in sheet metal forming using an evolutionary algorithm, Elsevier Science B.V., Journal of Materials Processing Technology 151, 183-191.

Giuliano, G. \& Franchitti, S. (2008). The determination of material parameters from superplastic free-bulging tests at constant pressure, Elsevier Science B.V., International Journal of Machine Tools \& Manufacture 48, 1519-1522.

Kappes, J., Liewald, M., Jupp, S., Pirchl, C. \& Herstelle, R. (2012). Designing superplastic forming process of a developmental AA5456 using pneumatic bulge test experiments and FE-simulation Prod. Eng. Res. Devel. 6:219-228, DOI 10.1007/s1 1740-012-0363-0.

Xing, H.L. \& Wang, Z.R. (1997). Finite-element analysis and design of thin sheet superplastic forming, Elsevier Science B.V., Journal of Materials Processing Technology $68,1-7$.

Chenot, J.-L. \& Massoni, E. (2006). Finite element modeling and control of new metal forming processes, Elsevier Science B.V., International Journal of Machine Tools \& Manufacture 46 pp. 1194-1200.

Bonet, J. \& Gil, A. J. (2011). Finite element modeling of thin metal sheet forming, published in Superplastic forming of advanced metallic materials, Methods, and Applications, Oxford, (C) Woodhead Publishing Limited.

Brown, S. B., Kim, K. H. \& Anand, L. (1989). An internal variable constitutive model for hot working of metals for hot working of metals, International Journal of Plasticity, Vol. 5, pp- 95-130.

Anand, L. (1985). Constitutive equations for hot-working of metals, International Journal of Plasticity, Vol. I, pp. 213-231.

Ganapathysubramanian, Sh. \& Zabaras, N. (2003). Computational design of deformation processes for materials with ductile damage, Comput. Methods Appl. Mech. Engrg. 192, 147-183, Elsevier Science B.V.

Jarrar, F., ( 2014 ). Designing gas pressure profiles for AA5083 superplastic forming, 11th International Conference on Technology of Plasticity, ICTP 2014, 19-24 October 2014, Nagoya Congress Center, Nagoya, Japan, ScienceDirect, Procedia Engineering $811084-1089$.

Guo, M.-L., Liu, J., Tan, M.-J., Chua, B.-W., ( 2014 ). Microstructure evolution of Ti6Al-4V during superplastic-like forming, 11th International Conference on Technology of Plasticity, ICTP 2014, 19-24 October 2014, Nagoya Congress Center, Nagoya, Japan, ScienceDirect, Procedia Engineering 81 1090 - 1095 